\title{
IMPACTS OF EMPLOYMENT RATES (DEMAND) AND PARTICIPATION RATES (SUPPLY) ON UNEMPLOYMENT RATES: A DISAGGREGATED ANALYSIS
}

\author{
Ram SriRamaratnam and Xintao Zhao \\ Ministry of Business, Innovation \& Employment \\ Wellington
}

\begin{abstract}
The interaction between the different macro labour market drivers and their influence on key labour market outcomes is of considerable interest to labour market analysts as well as policy makers. One of these relationships is between employment growth (or labour demand) and the associated reduction in the unemployment rate. This relationship is often determined by other labour market indicators, such as participation rates (or labour supply), and the working age population (amongst other factors). This paper reports on an integrated macro labour market forecasting framework developed by the Labour Group of MBIE, disaggregated into 11 five-yearly age cohorts across the working age population.

The labour market dynamics during business cycles are affected by the ageing of the work force in New Zealand. This has varied consequences on labour market outcomes for different age cohorts, especially those at each end of the age spectrum. Forecasting likely future unemployment rates by age cohort level is of considerable interest, and will provide further insights into labour market dynamics. In addition to those in the prime age cohorts, other cohorts of interest include new entrants into the working age population; those age cohorts potentially involved in training; and those in the pre-retirement age cohorts.
\end{abstract}

\section{Introduction}

This paper reports on a disaggregated analysis of macro labour market drivers of unemployment rates studied at the aggregate level and reported earlier this year (SriRamaratnam et. al, 2012). The disaggregation is carried out for 5-year age cohorts and applies the conceptual framework used for the aggregate analysis across the total labour force.

The material covered in this paper commences with a review of the recent changes in these macro labour market drivers of unemployment rate both on the demand side (employment rates) and supply side (participation rates). This is followed by a discussion of the changes in employment rates and participation rates across these 11 age cohorts and the rationale for carrying out a disaggregated analysis to gain further insights of the dynamics of the labour market.

An outline of the modelling framework adopted to capture the relationship between employment rates and participation rates and how they align with the working age population projections by age cohorts to determine the levels of unemployment rates is explained next.

Finally, some preliminary forecasts of unemployment rates by age cohorts and the factors likely to be influencing the different rates of changes are reported. This is undertaken across: (a) the prime age cohorts; (b) the new entrants to the working age population; (c) those potentially involved in training; and (d) those in the preretirement age cohorts.

The relationship between employment growth and the associated reduction in the unemployment rate, for example, is often determined by other labour market indicators such as participation rates and growth in the working age population. The focus of this paper is to introduce an integrated macro-labour market forecasting framework developed by the Ministry of Business, Innovation \& Employment (MBIE) Labour Group to capture these relationships in a systematic and sequential way and provide some useful applications.

\section{Macro-labour market drivers of unemployment rates - recent experiences}

\section{Employment rates and Unemployment rates}

The employment rate increased rapidly by about 3\% from 63\% to 66\% between March quarter 2003 and December quarter 2007 (Figure 1). During the same period, the unemployment rate also decreased from about $5 \%$ to well below 4\%. Between March quarter 2008 and December quarter 2009, with the onset of the economic downturn 
and the Global Financial Crisis (GFC), the employment rate declined back to around $63 \%$ and the unemployment rate increased to about 7\%. From March quarter 2010 to March quarter 2012, the employment rate has risen somewhat to about $64 \%$ but the unemployment rate has remained at around $6.5 \%$.

Figure 1: Historical employment and unemployment rates

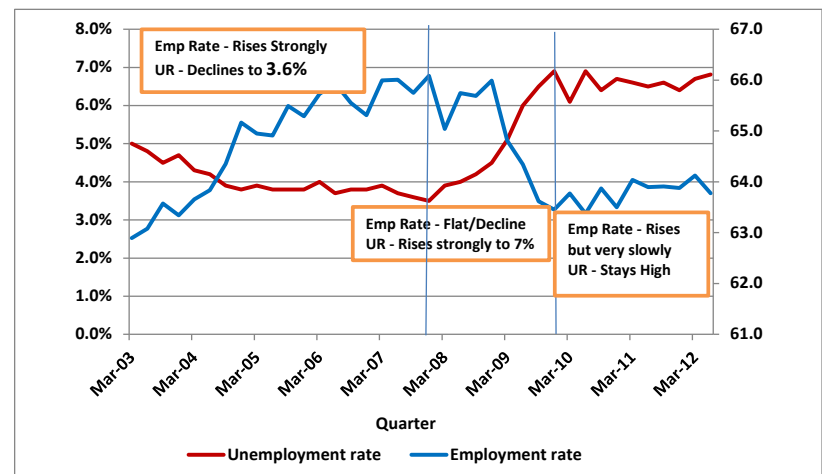

Hence the relationship between the employment rate and the unemployment rate can be summarized as follows:

- During 2003-07, the employment rate rose by $3 \%$ to $4 \%$ which was enough to drive the unemployment rate down to below $4 \%$.

- Conversely, the employment rate decline of $1 \%$ to $2 \%$ from $2008-10$ led to the unemployment rate rising to $7 \%$ in late 2009 and mid-2010.

- Despite the employment rate rise of $1 \%$ to $2 \%$ since then and throughout 2011, the unemployment rate has remained at around $6.5 \%$ for much of the 2011 calendar year and rose to $6.8 \%$ in June.

\section{Participation rates and Unemployment rates}

Between March quarter 2003 and December quarter 2007, the participation rate increased quite rapidly (Figure 2). During this period, the unemployment rate also decreased rapidly below 4\%. During March quarter 2008 to March quarter 2012, the participation rate remained flat initially but has increased somewhat since December quarter 2010. But the unemployment rate rose sharply between December quarter 2007 and December quarter 2009 and was flat since then before rising in the latest June quarter 2012.
Figure 2: Historical participation and unemployment rates

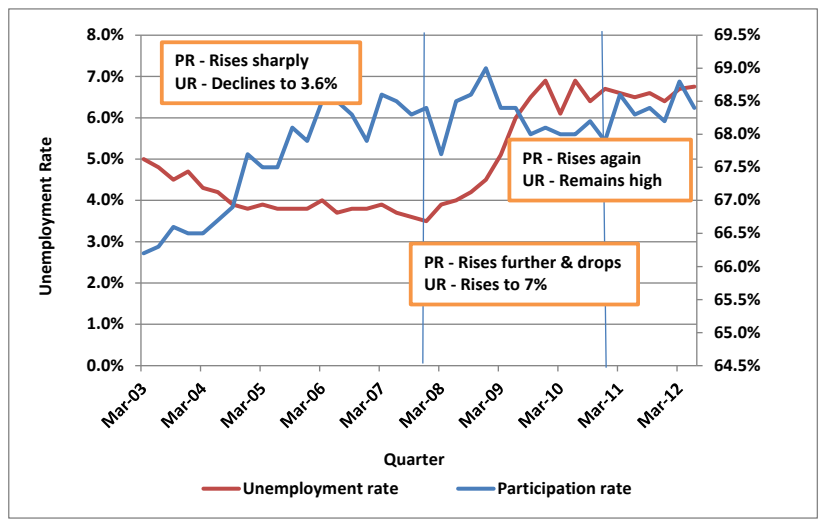

In summary, the following developments could be seen over the 10 year historical period:

- $\quad$ The participation rate rose from $65 \%$ to over $68 \%$ while employment growth rate was between $2 \%$ to $4 \%$ and the unemployment rate declined from above $5 \%$ to well below 4\% during the 2003 to 2007 period,

- The participation rate remained high during the 2007-08 period when employment growth weakened and the unemployment rate rose.

- Over the period from 2008-10, the participation rate declined somewhat when the unemployment rate remained flat at above $6.5 \%$ and when employment growth was positive but weak.

\section{Model Structure}

The framework below requires limited inputs, with aggregate employment growth forecasts and the workingage population being the only exogenous drivers, and is set up in a combined structural and time series estimation framework and in seasonally adjusted terms. 


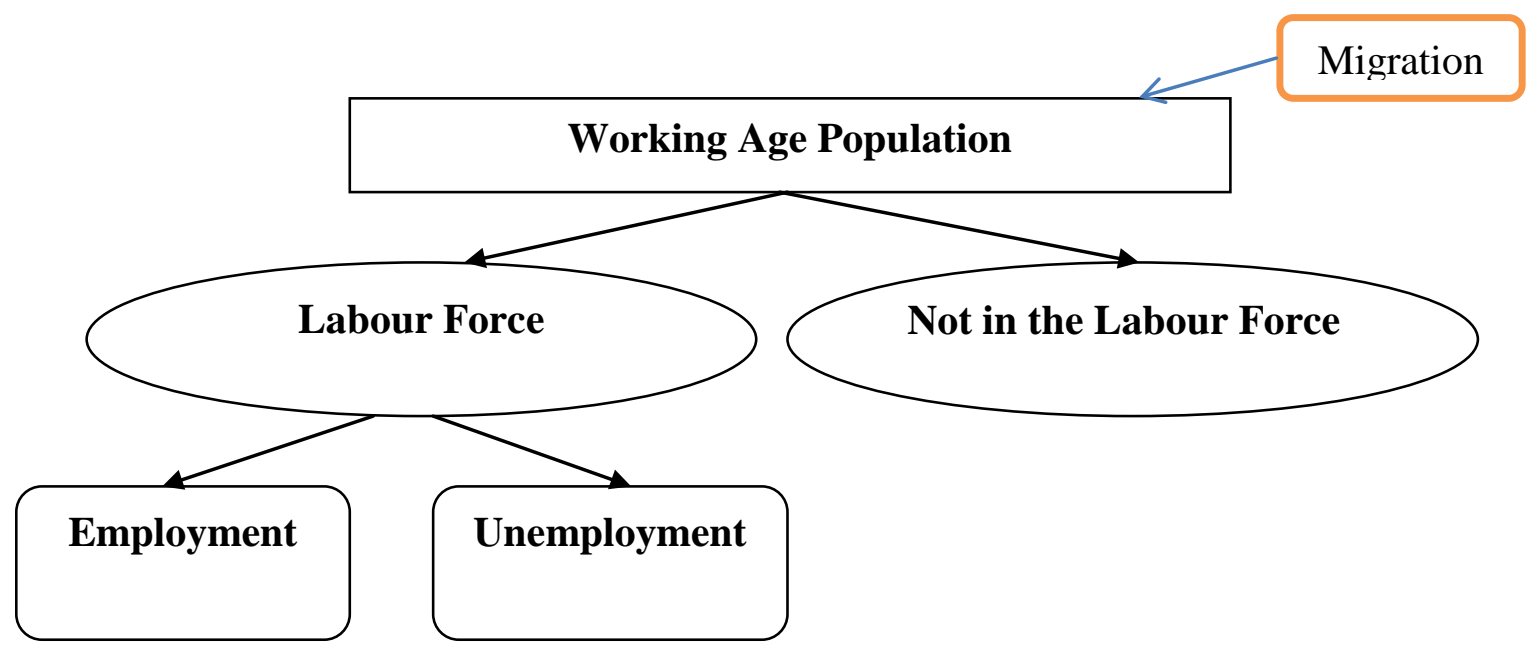

1) Overall Labour Market Components

In the overall labour market, working age population consists of the labour force and those not in the labour force. The labour force includes those in employment and in unemployment. Migration along with the natural rate of population growth impacts on the working age population.

\section{2) Factors Influencing Unemployment Rate Changes}

Employment (demand) is an important factor that influences unemployment rate changes. When employment increases (or decreases) and labour force is unchanged, unemployment rate decreases (or increases). Working age population (supply) is also an important factor that impacts on unemployment rate changes. If working age population changes lead to labour force changes and employment growth is unchanged, unemployment rate changes.

\section{Equations in the Model}

There are some derivations and identities in this forecasting framework as follows:

$$
\begin{array}{ll}
\text { 1. } & E R_{\mathrm{t}}=\frac{E M P_{\mathrm{t}}}{W A P_{\mathrm{t}}} \\
\text { 2. } & L F_{\mathrm{t}}=P R_{\mathrm{t}} * W A P_{\mathrm{t}} \\
\text { 3. } & N I L F_{\mathrm{t}}=W A P_{\mathrm{t}}-L F_{\mathrm{t}} \\
\text { 4. } & U E_{\mathrm{t}}=L F_{\mathrm{t}}-E M P_{\mathrm{t}} \\
\text { 5. } & U R_{\mathrm{t}}=\frac{U E_{\mathrm{t}}}{L F_{\mathrm{t}}}
\end{array}
$$

In which;

$E M P_{t}=$ Employment level

$W A P_{t}=$ Working age population
$E R_{t}=$ Employment rate

$P R_{t}=$ Participation rate

$L F_{t}=$ Labour force

$N I L F_{t}=$ Not in the Labour Force

$U E_{t}=$ Unemployment level

$U R_{t}=$ Unemployment rate.

\section{Model Estimation}

1) Aggregate analysis of employment growth forecasts:

The short-term employment forecast model developed by MBIE-Labour was employed to produce quarterly employment growth over the next 8 quarters. This is an econometric model that produces quarterly GDP and employment forecast at the industry level that is aggregated to derive total quarterly employment growth.

2) Disaggregated Employment rate and Participation rate analysis and forecasts:

In order to forecast the participation rate for the age cohorts using its lags and current \& lagged employment rates, 11 linear regressions were estimated to forecast employment rates by age cohorts. The 11 equations are for the full spectrum of 5 yearly age cohorts from age 15 to $65+$ covering $15-19,20-24,25-29,30-34,35-39,40-$ 44, 45-49, 50-54, 55-59, 60-64 and 65+ age cohorts, respectively.

In each of these equations, the dependent variable is the changes in employment rate of corresponding age cohort in logarithmic terms, integrated to the order 1 . The independent variables may be changes in lagged dependent variable and changes in lagged employment 
rate for other age cohorts in logarithmic terms, integrated to the order 1 . The form of the equations is as follows:

$$
D L E R_{i t}=\alpha_{i} D L E R_{i, t-p}+\beta_{j} D L E R_{j, t-q}+\epsilon_{i t}
$$

Where $\mathrm{i}, \mathrm{j}$ denotes age cohort and $\mathrm{i} \neq \mathrm{j}, \mathrm{t}$ is the quarterly time period, $\mathrm{p}=1,2,3, \ldots, \mathrm{m}$ and $\mathrm{q}=1,2, \ldots, \mathrm{n}$.

The estimated disaggregated employment rate equations are reported in Appendix B. Changes in lagged employment rates for the same age cohorts are found to be significant in some of the employment rate equations. Changes in lagged employment rates for adjacent and non-adjacent age cohorts are significant in other equations often along with changes in lagged own employment rates.

Then a set of disaggregated equations for participation rates by age cohorts were also estimated and are reported in Appendix C. In the 11 equations used to forecast participation rates, the same spectrum of age cohorts are used as in the above 11 equations to forecast employment rates by age cohorts.

In each of these equations, the dependent variable is the changes in participation rate of corresponding age cohort in logarithmic terms, integrated to the order 1 . The independent variables include changes in lagged dependent variables, changes in current employment rate and changes in lagged employment rate (of various lags) in logarithmic terms, integrated to the order 1 . The form of the equations is as follows:

$$
D L P R_{i t}=\gamma_{i} D L P R_{i, t-p}+\delta_{i} D L E R_{i, t-q}+\theta_{i t}
$$

Where i denotes age cohort, $\mathrm{t}$ is the quarterly time period, $\mathrm{p}=1,2,3, \ldots, \mathrm{r}$ and $\mathrm{q}=0,1,2, \ldots, \mathrm{s}$.

In all of the disaggregated participation rate equations, the participation rate in the previous quarter for the same age cohort was found to be significant at the $1 \%$ level of confidence. In some of the participation rate equations the participation rates in quarters further lagged by 2-4 quarters were also found to be significant.

But the important additional dimension captured in explaining the changes in participation rates was the influence of changes in employment rates. In the case of each age cohort, the participation rate was impacted by employment rates for the same quarter without exception, with the coefficients also significant at the $1 \%$ level of confidence. In addition, the changes in employment rates for quarters further lagged were also found to be significant.

\section{Historical employment and participation rates changes - for illustrative age cohorts}

The employment rates and participation rates are important factors that affect the changes in unemployment rates. In Figure 3, the employment rate changes for six out of the eleven 5-yearly age cohorts have been presented for the historical (2002-12 March year) and forecast (2012-14) periods. In figure 4, the changes in participation rates for the same age cohorts are presented. These age cohorts are chosen to illustrate the types of changes for the prime age cohorts along with those for the younger and older age cohorts.

The younger age cohorts include the new entrants (15-19 year olds) to the working age population as well as those (20-24 year olds) potentially involved in training. The prime age cohorts (35-39 and 40-44 year olds) which include the pre-peak and peak age groups are used to contrast the differences in changes in employment and participation rates with the younger and older preretirement (55-59 and 60-64 year olds) age cohorts which could be considered to be in the post-peak age groups.

Figure 3: Historical and forecast employment rates

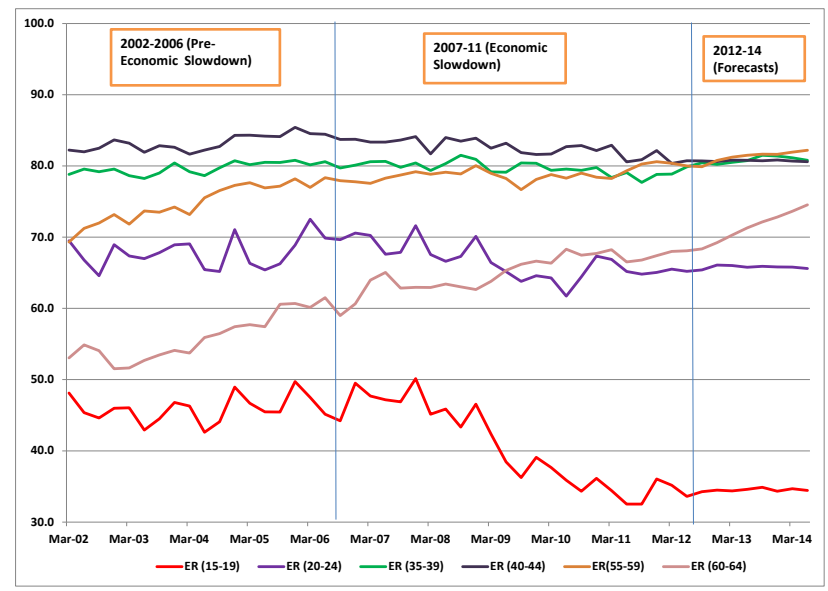

The average values (means) and volatility in employment rates and participation rates measured as the coefficient of variation are summarised in Appendix D:

The figures in Part A (of Appendix D) suggest that:

1) the age cohorts which had seen the greatest changes in employment rates over the two historical sub-periods (2002-06 and 2007-11) are those representing the

1) "Entrants" to the working age population (15-19 age group)

2) The “Trainees” (20-24) age cohort

3) The post-peak (pre-retirement) age cohorts (the 60-64 age cohort in particular) and

4) The 65+ age cohort which includes the "potential retirees".

2) the age cohorts which had seen the least changes in employment rates over the two historical subperiods (2002-06 and 2007-11) are those covering the 
a) Pre-peak (30-34) age cohort and

b) Peak (40-44 and 45-49) age cohorts

Figure 4: Historical and forecast participation rates

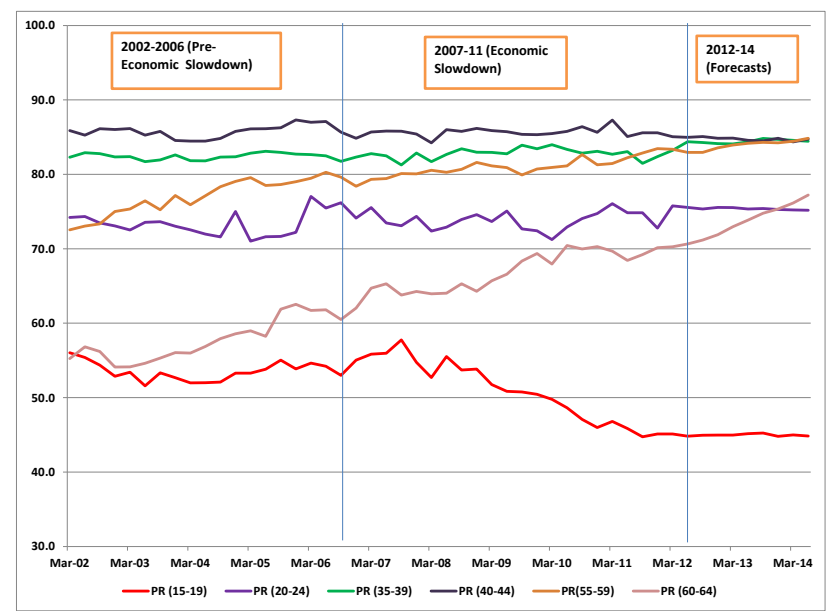

The figures in Part B (of Appendix D) suggest that:

1) the age cohorts which had seen the greatest changes in participation rates over the two historical sub-periods (2002-06 and 2007-11) are those representing the

a) "Entrants" to the working age population (15-19 age group)

b) The post-peak participation rate age cohorts (the 60-64 age cohort in particular) and

c) The 65+ age cohort which includes the "potential retirees".

2) the age cohorts which had seen the least changes in participation rates over the two historical sub-periods (2002-06 and 2007-11) are those covering the

a) Pre-peak participation rate ( 35-39) age cohort

b) Peak participation rate (40-44 and 45-49) age cohorts and to some extent

c) The “Trainees” (25-29) age cohort.

\section{Forecasts of unemployment rates based on forecast employment and participation rates - for illustrative age cohorts}

The forecasts based on the equations reported in Part B of Appendix D indicate that the decline in the participation rate of the entrants to the labour market (15-19 age cohort) seen during the 2007-11 period in particular may have bottomed out while the participation rate of those in the older age cohorts, both post peak 60-64 age cohort and the potential retiree $65+$ age cohort, is likely to continue to rise at recent historical growth rates.

In this section, the employment rates and participation rates are presented for the historical period (2009 - 2012) and forecasts for the next two years (2013 and 2014) for the same illustrative age cohorts. This covers the younger age cohorts, prime age cohorts and older age cohorts. The corresponding unemployment rates are also reported to understand the likely impacts of the changes in employment rates and participation rates.

\section{Younger age cohorts: (15-19 and 20-24 years)}

In the case of the youngest age cohort (15-19 year olds), the employment rate and participation rate had declined steadily over the 2009 to 2011 period and had started to stabilise in 2012 and is forecast to decline very slightly. This results in the unemployment rate declining very slightly due to the decline in participation rates.

In the case of the next older age cohort (20-24 year olds) who are likely to be involved in (secondary and tertiary) training, there was recent volatility in both employment and participation rate and both are forecast to stabilise. But due to the slight rise in employment rate and decline in participation rate, the unemployment rate is forecast to decline somewhat more than for the new entrants to the working age population (15-19 year olds).

\section{Prime age cohorts: (35-39 and 40-44 years)}

The cohorts in the prime age groups (35-39 and 40-44 year olds) presented here are about 20 years older than the younger age cohorts. There was volatility in both employment rates and hence participation rates over the 2009 to 2011 period in the case of both of these age cohorts resulting in some (1-2\%) rise in unemployment rate for the 35-39 age cohort but significant (over 2\%) rise in unemployment rate for the $40-44$ age cohort. 
Comparison of ER, PR and UR: 15-19 Age Cohort

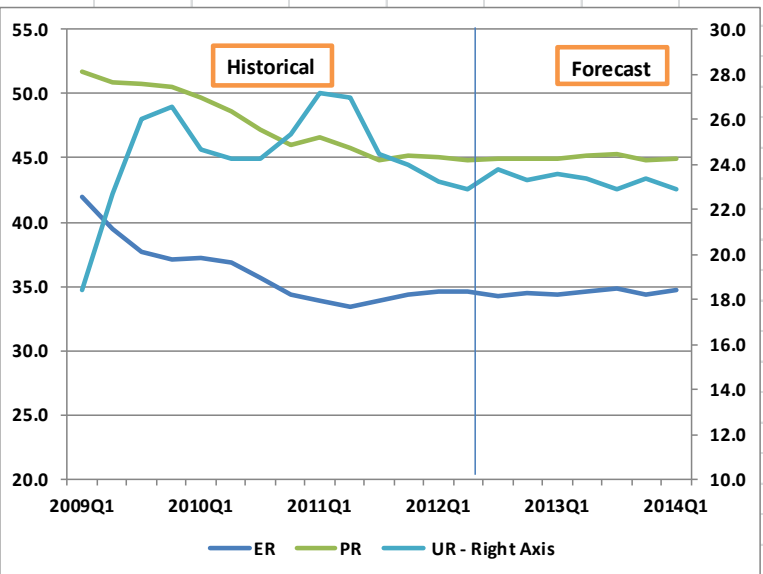

Comparison of ER, PR and UR: 20-24 Age Cohort

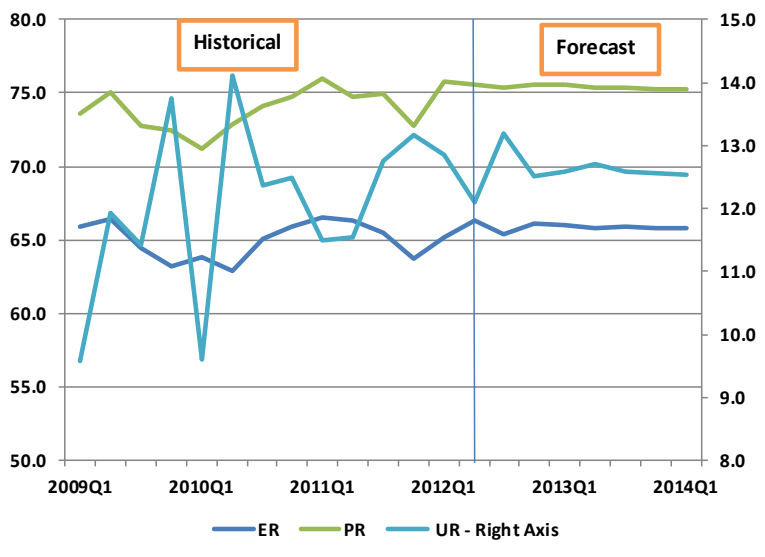

Given that both the employment rate and the participation rate have been rising since 2011 in the case of the 35-39 age cohort and is expected to rise further, the unemployment rate is forecast to decline by over $1 \%$. In the case of the older of the two prime age cohorts (40-44 year olds) presented here, with participation rate considerably higher (by about 2-3\%) but employment rate similar, the decline in unemployment rate over the next two years is forecast to be less than $1 \%$.

\section{Older age cohorts: (55-59 and 60-64 years)}

The older age cohorts (55-59 and 60-64 year olds) presented are 20 years older than the prime age cohorts discussed above and 40 years older than the younger age cohorts. These older age cohorts saw steady increase in both employment and participation rates during the 20092012 period and significant volatility in unemployment rate albeit at a lower level around $2.5 \%$ and $4.0 \%$.

The rising recent trend in both employment rates and participation rates amongst these older age cohorts, especially for the older 60-64 age group, is forecast to continue over the forecast period. But the actual rates are considerably lower than for the prime age cohorts, particularly in the case of the 60-64 year age cohort. This is expected to lead to about $1 \%$ decline in the unemployment rate. See Appendix A for further insights and analysis of the labour force shares for the different age cohorts and forecast changes over the next two years.
Comparison of ER, PR and UR: 35-39 Age Cohort

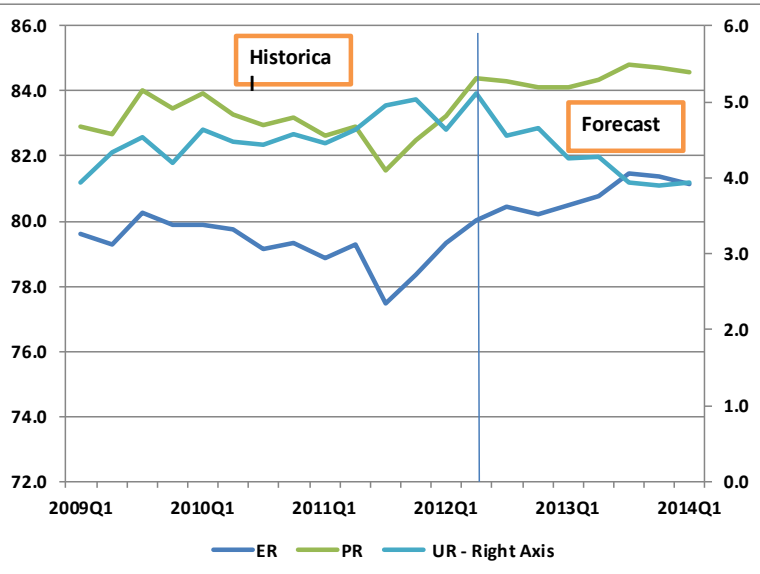

Comparison of ER, PR and UR: 40-44 Age Cohort

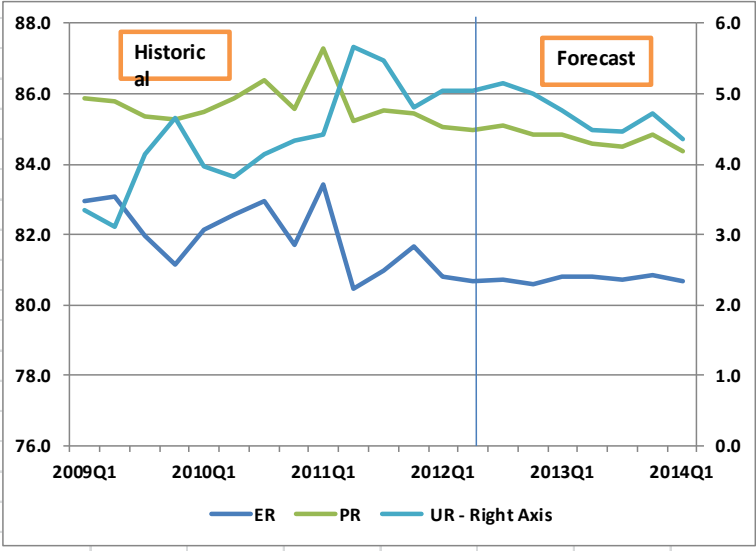

Comparison of ER, PR and UR: 55-59 Age Cohort

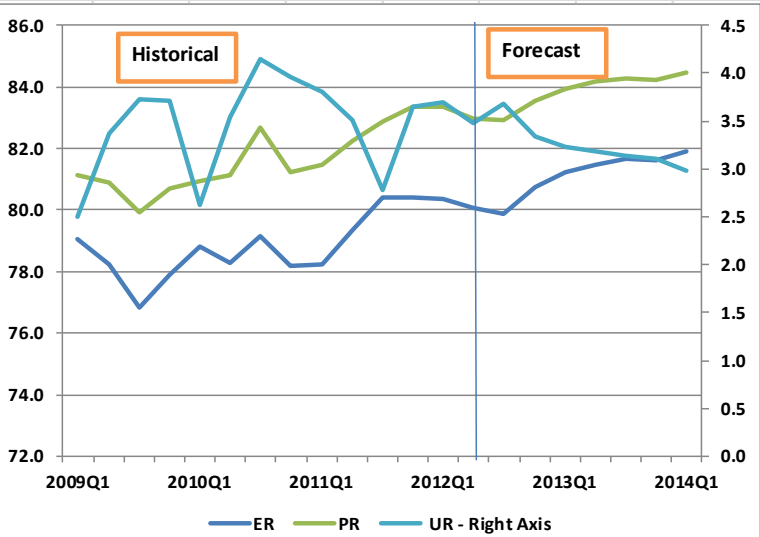

Comparison of ER, PR and UR: 60-64 Age Cohort

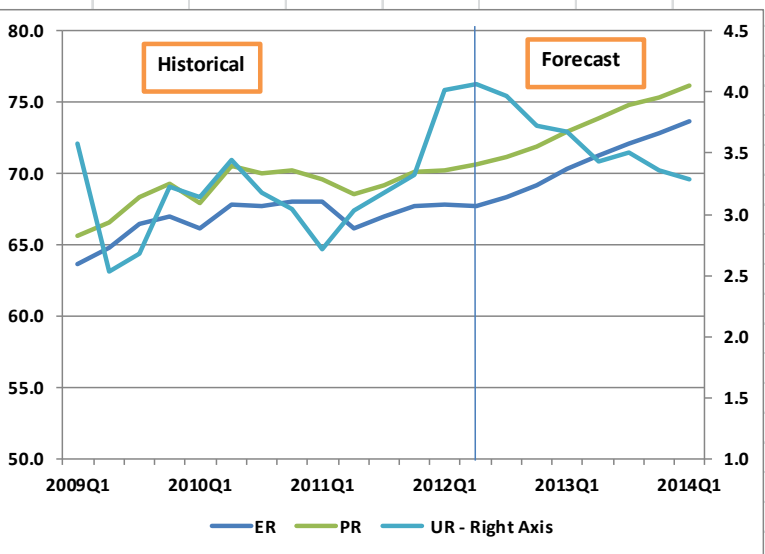




\section{Conclusions}

The method described here is an extension of an integrated macro-labour market forecasting framework originally developed to forecast short-term unemployment rates within the Ministry at the aggregate level. It is used for the purposes of updating the Department's Quarterly Labour Market Update where the implications of the latest available economic and labour market information from GDP and HLFS release are studied and reported. In addition, the aggregate model provides the forecasts of other important labour market components such as participation rate, labour force growth and so on. Based on these forecasts, the trends in key macro labour market components and relationship between the different macro labour market drivers could be assessed better.

In this paper, the findings from the disaggregated analysis of the impacts of macro labour market factors covering both demand and supply on unemployment rates are reported. The focus was on the impacts of employment rates and participation rates on unemployment rates for 5yearly age cohorts covering the younger, prime (or peak participation) and older (pre-retirement) age cohorts. This analysis extends the recent work by MBIE-Labour group which investigated these effects at the aggregate level across the entire work force.

Employment growth across age cohorts translates to employment rates and influences the participation rates of those in these age cohorts along with lagged participation rates. Employment rates are also influenced by employment rates of those in adjacent age cohorts along with lagged employment rates. Working age population across the age cohorts and the projections are sourced from SNZ

The gradual reduction in aggregate unemployment rate expected to occur over the next two years is expected to be spread across the different age cohorts. Some of the prime age cohorts and older age cohorts see greater reduction in unemployment rate due to rising employment rates. Some unemployment rates reduction for younger age cohorts arises mainly from further reduction in participation rates rather than rising employment rates.

\section{References}

Patrick Conway and Simon McLoughlin (2002). 'Labour market trends and outlook 2002', Labour Market Bulletin 2000-02, Special Issue, Department of Labour, New Zealand.

Peter Gardiner and Kirdan Lees (2011). 'Forecasting New Zealand's labour market with multiple datasets', presented to the 2011 NZAE Conference, Wellington, June.

Ram SriRamaratnam Xintao Zhao and Will Bell (2012), 'Employment growth and unemployment reduction: Historical Experiences and future labour market outcomes', presented to the 2012 NZAE Conference, Palmerston North, June.

Statistics New Zealand, Data releases (Household Labour Force Survey - HLFS) and Projections (Working age population - medium fertility, medium mortality and net migration $=5,000$ ). 


\section{Appendix A:}

\section{Recent and forecast Working age population (WAP) its components (LF and NILF) and Employment levels}

Both working age population and the employment levels are forecast to rise over the next two years, the latter slightly more than the former. The labour force is also forecast to rise over this period while those not in the labour force is forecast to remain relatively unchanged.

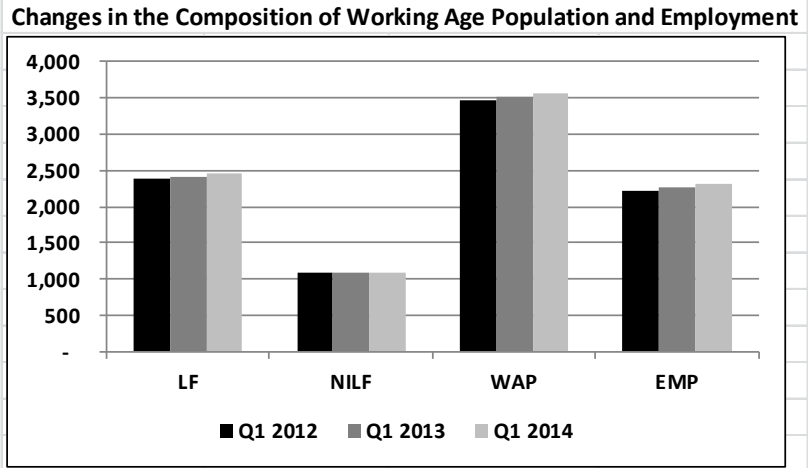

\section{Composition of the Working age population Labour force \& not in the Labour force}

In this section, the implications and the actual dynamics of the above forecasts are investigated by examining the composition of the working age population which consists of the labour force (LF) and those not in the labour force (NILF).

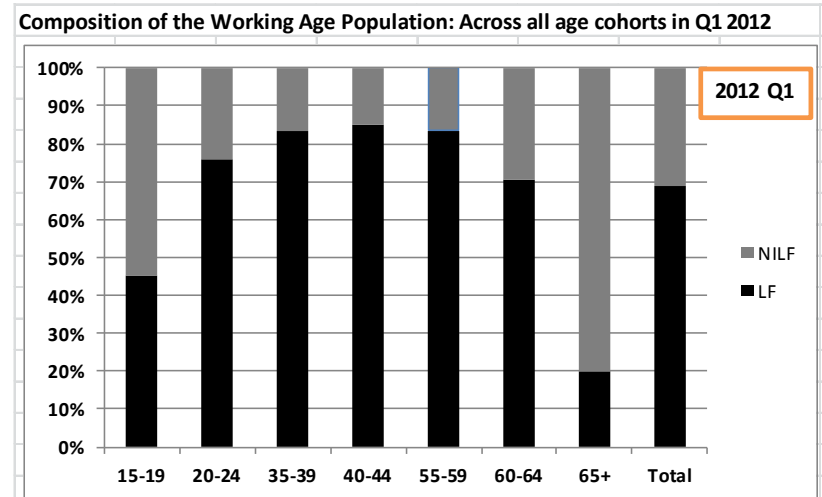

The share of the labour force in the working age population for the entire labour market is forecast to rise gradually over the two years from 2012 March quarter to 2014 March quarter from about $68.8 \%$ to about $69.3 \%$.

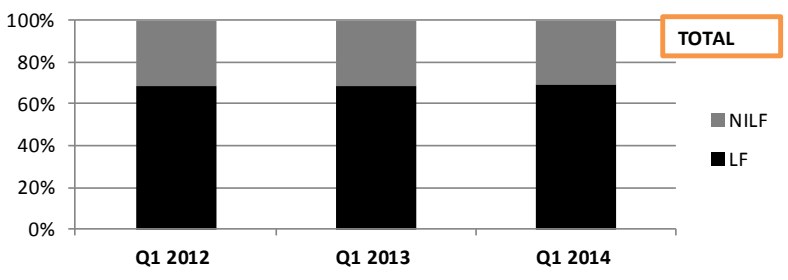

The composition is expected to be different for the youngest (15-19 age group) and the older age cohorts (ie, greater share of NILF for different reasons) in comparison to prime age cohorts (ie, greater share of LF).

\section{Younger age cohorts: (15-19 and 20-24)}

There is a sharp contrast in the share of the LF in the case of the youngest (15-19 age group) age cohort (about 40\%) in comparison to the next older 20-24 age group (about $75 \%)$. This is attributable to the schooling and training emphasis for these age cohorts and the share of LF is forecast to remain relatively unchanged over the next two years.

\section{Prime age cohorts: (35-39 and 40-44)}

The share of the LF is considerably larger (over 80\%) for the prime age cohorts in comparison to the younger age cohorts discussed before as these are age cohorts which are primarily focused on work with the exception of some with other responsibilities or participation in re-training making them unable to work. The share of those in LF is forecast to rise very gradually over the next two years.

\section{Older age cohorts: (55-59 and 60-64)}

The share of the LF amongst the older age cohorts drops off sharply with rising age as many workers withdraw their services from the work force. This can be seen when comparing the share of LF for the 55-59 year olds (almost $80 \%$ ) with the $60-64$ year olds (about 70\%) in 2012. But the share of LF is forecast to rise to about $75 \%$ for the 60 64 year olds by 2014.

\section{Oldest age cohort: (65+ Category)}

The share of the LF for the oldest age cohort which includes all of the workers who are 65 years and older is very low at about $20 \%$ and is expected to rise to just over $20 \%$ by 2014. 
Composition of the Working Age Population: Older age cohorts
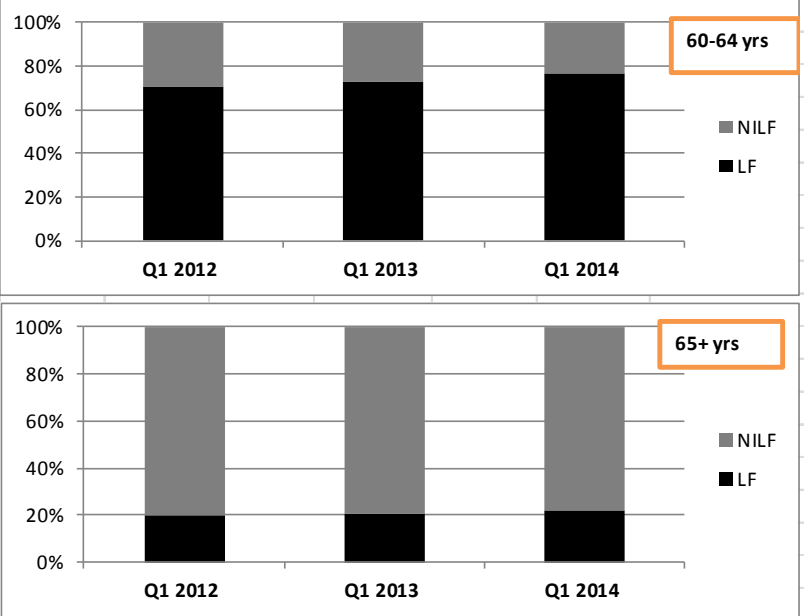
Appendix B: Disaggregated Employment Rate Forecast Equations by Age Cohorts (based on average net migration=5,000)

\begin{tabular}{|c|c|c|c|c|c|c|c|c|c|c|c|}
\hline \multirow{2}{*}{$\begin{array}{c}\text { Items } \\
\text { Independent } \\
\text { Variables } \\
\end{array}$} & \multicolumn{11}{|c|}{ Dependent Variables - Changes in Employment Rates (DLER) by Age Cohorts } \\
\hline & $15-19$ & $20-24$ & $25-29$ & 30-34 & 35-39 & 40-44 & 45-49 & $50-54$ & $55-59$ & $60-64$ & $65+$ \\
\hline DLER2024(-1) & & $-0.383 * * *$ & & & & & & & & & \\
\hline DLER2024(-3) & & $0.201 * *$ & & & & & & & & & \\
\hline DLER2024(-5) & $0.353 * * *$ & & & & & & & & & & \\
\hline DLER2024(-9) & $0.315^{* *}$ & & $0.116^{* *}$ & & & & & & & & \\
\hline DLER2529(-2) & & & & $0.201 * *$ & & & & & & & \\
\hline DLER2529(-4) & & & $-0.327 * * *$ & & & & & & & & \\
\hline DLER2529(-14) & & & & $-0.165^{*}$ & & & & & & & \\
\hline DLER3034(-1) & & & & $-0.318 * * *$ & & & & & & & \\
\hline DLER3539(-5) & & & & & $0.219 * *$ & & & & & & \\
\hline DLER3539(-8) & & & & & $-0.291 * * *$ & & & & & & \\
\hline DLER3539(-10) & $-0.748 * *$ & & & & & & & & & & \\
\hline DLER4044(-1) & & & & & $0.231 * *$ & $-0.262 * * *$ & & & & & \\
\hline DLER4044(-2) & & & & & $-0.195^{* *}$ & & & & & & \\
\hline DLER4549(-1) & & & $0.285^{*}$ & & & & $-0.238 * * *$ & & & & \\
\hline DLER4549(-2) & & & & & & $0.221 * *$ & & & & & \\
\hline DLER4549(-5) & & & & & & & $-0.162^{*}$ & & & & \\
\hline DLER4549(-7) & & & & & & $0.229 * *$ & & & & & \\
\hline DLER4549(-8) & & & & & & & $-0.273 * * *$ & & & & \\
\hline DLER5054(-8) & & & & & & & & $-0.178 *$ & & & \\
\hline DLER5054(-12) & & & & & & & & $-0.200^{* *}$ & & & \\
\hline DLER5559(-4) & & & & & & & & & $-0.316 * * *$ & & \\
\hline DLER5559(-5) & & & & & & & & & $0.227^{* *}$ & & \\
\hline DLER5559(-6) & & & & & & & & & $0.206 * *$ & & \\
\hline DLER5559(-11) & & & & & & & & $0.296 * * *$ & & & \\
\hline DLER6064(-1) & & & & & & & & & & $0.291 * * *$ & \\
\hline DLER6064(-4) & & & & & & & $0.060 * * *$ & & & $-0.164 * * *$ & \\
\hline DLER6064(-5) & & & & & & & & & $0.102 * * *$ & & \\
\hline DLER6064(-17) & & & & & & & & & & $-0.173 * * *$ & \\
\hline
\end{tabular}




\begin{tabular}{|c|c|c|c|c|c|c|c|c|c|c|c|}
\hline DLER65over(-9) & & & & & & & & & & & $0.170^{*}$ \\
\hline DLER65over(-10) & & & & & & & & & & & $0.255^{* * *}$ \\
\hline DLER65over(-11) & & & & & & & & & & & $0.183^{*}$ \\
\hline R-squared & 0.160 & 0.166 & 0.149 & 0.144 & 0.273 & 0.189 & 0.190 & 0.162 & 0.256 & 0.157 & 0.136 \\
\hline $\begin{array}{l}\text { Adjusted } \\
\text { R-squared }\end{array}$ & 0.133 & 0.149 & 0.121 & 0.115 & 0.242 & 0.163 & 0.154 & 0.134 & 0.224 & 0.127 & 0.107 \\
\hline $\mathbf{F}$ & 5.791 & 9.828 & 5.360 & 4.880 & 8.655 & 7.310 & 5.378 & 5.727 & 8.082 & 5.205 & 4.731 \\
\hline AIC & -4.324 & -4.863 & -5.869 & -6.232 & -6.646 & -6.577 & -6.632 & -6.242 & -6.227 & -4.500 & -3.345 \\
\hline
\end{tabular}

Appendix C: Disaggregated Participation Rates Forecasting Equations by Age Cohorts (based on average net migration=5,000)

\begin{tabular}{|c|c|c|c|c|c|c|c|c|c|c|c|}
\hline \multirow{2}{*}{$\begin{array}{c}\text { Items } \\
\begin{array}{c}\text { Independent } \\
\text { Variables }\end{array}\end{array}$} & \multicolumn{11}{|c|}{ Dependent Variables - Changes in Participation Rates (DLPR) by Age Cohorts } \\
\hline & $15-19$ & $20-24$ & $25-29$ & $30-34$ & $35-39$ & $40-44$ & $45-49$ & $50-54$ & $55-59$ & $60-64$ & $65+$ \\
\hline DLPR1519(-1) & $-0.287 * * *$ & & & & & & & & & & \\
\hline DLPR1519(-4) & $-0.229 * * *$ & & & & & & & & & & \\
\hline DLPR2024(-1) & & $-0.400 * * *$ & & & & & & & & & \\
\hline DLPR2529(-1) & & & $-0.394 * * *$ & & & & & & & & \\
\hline DLPR3034(-1) & & & & $-0.308 * * *$ & & & & & & & \\
\hline DLPR3034(-4) & & & & $-0.190 * * *$ & & & & & & & \\
\hline DLPR3539(-1) & & & & & $-0.240 * * *$ & & & & & & \\
\hline DLPR4044(-8) & & & & & & $-0.336 * * *$ & & & & & \\
\hline DLPR4549(-1) & & & & & & & $-0.356 * * *$ & & & & \\
\hline DLPR4549(-2) & & & & & & & $-0.125 * *$ & & & & \\
\hline DLPR4549(-3) & & & & & & & $0.164^{*}$ & & & & \\
\hline DLPR5054(-1) & & & & & & & & $-0.469 * * *$ & & & \\
\hline DLPR5559(-1) & & & & & & & & & $-0.339 * * *$ & & \\
\hline DLPR6064(-1) & & & & & & & & & & $-0.478 * * *$ & \\
\hline DLPR6064(-2) & & & & & & & & & & $0.052 * *$ & \\
\hline DLPR6064(-4) & & & & & & & & & & $-0.327 * * *$ & \\
\hline DLPR65over(-1) & & & & & & & & & & & $-0.540 * * *$ \\
\hline DLER1519 & $0.653 * * *$ & & & & & & & & & & \\
\hline DLER1519(-1) & $0.189 * *$ & & & & & & & & & & \\
\hline
\end{tabular}




\begin{tabular}{|c|c|c|c|c|c|c|c|c|c|c|c|}
\hline DLER1519(-4) & $0.182 * *$ & & & & & & & & & & \\
\hline DLER2024 & & $0.559 * * *$ & & & & & & & & & \\
\hline DLER2024(-1) & & $0.202 * * *$ & & & & & & & & & \\
\hline DLER2529 & & & $0.559 * * *$ & & & & & & & & \\
\hline DLER2529(-1) & & & $0.216 * *$ & & & & & & & & \\
\hline DLER3034 & & & & $0.611^{* * *}$ & & & & & & & \\
\hline DLER3034(-1) & & & & $0.172 * *$ & & & & & & & \\
\hline DLER3539 & & & & & $0.574 * * *$ & & & & & & \\
\hline DLER3539(-6) & & & & & $0.126^{* * *}$ & & & & & & \\
\hline DLER4044 & & & & & & $0.697 * * *$ & & & & & \\
\hline DLER4044(-1) & & & & & & $-0.160 * * *$ & & & & & \\
\hline DLER4044(-8) & & & & & & $0.277^{* * *}$ & & & & & \\
\hline DLER4044(-12) & & & & & & $-0.096^{*}$ & & & & & \\
\hline DLER4549 & & & & & & & $0.731 * * *$ & & & & \\
\hline DLER4549(-1) & & & & & & & $0.167^{* *}$ & & & & \\
\hline DLER4549(-3) & & & & & & & $-0.230 * * *$ & & & & \\
\hline DLER4549(-7) & & & & & & & $-0.114 * * *$ & & & & \\
\hline DLER5054 & & & & & & & & $0.714^{* * *}$ & & & \\
\hline DLER5054(-1) & & & & & & & & $0.317^{* * *}$ & & & \\
\hline DLER5559 & & & & & & & & & $0.800 * * *$ & & \\
\hline DLER5559(-1) & & & & & & & & & $0.234^{* * *}$ & & \\
\hline DLER6064 & & & & & & & & & & $0.938 * * *$ & \\
\hline DLER6064(-1) & & & & & & & & & & $0.435^{* * *}$ & \\
\hline DLER6064(-4) & & & & & & & & & & $0.326 * * *$ & \\
\hline DLER65over & & & & & & & & & & & $0.983 * * *$ \\
\hline DLER65over(-1) & & & & & & & & & & & $0.494 * * *$ \\
\hline R-squared & 0.705 & 0.628 & 0.549 & 0.646 & 0.599 & 0.788 & 0.815 & 0.720 & 0.674 & 0.954 & 0.943 \\
\hline $\begin{array}{c}\text { Adjusted } \\
\text { R-squared }\end{array}$ & 0.690 & 0.617 & 0.536 & 0.632 & 0.586 & 0.775 & 0.801 & 0.712 & 0.664 & 0.951 & 0.941 \\
\hline $\mathbf{F}$ & 45.421 & 56.245 & 40.598 & 43.892 & 47.241 & 64.553 & 56.653 & 85.769 & 68.984 & 325.440 & 318.992 \\
\hline AIC & -5.620 & -6.164 & -6.890 & -7.292 & -7.711 & -8.075 & -8.286 & -7.456 & -7.123 & -7.118 & -6.019 \\
\hline
\end{tabular}


Appendix D: Summary Measures for Disaggregated Employment Rates \& Participation Rates by Age Cohorts (Historical \& Forecasts)

A: Employment Rate by age cohorts: Historical (2002-2012 June Qtr) and Forecasts (2013-2014)

\begin{tabular}{|c|c|c|c|c|c|c|c|c|c|c|c|}
\hline Averages & PR (15-19) & PR (20-24) & PR (25-29) & PR (30-34) & PR (35-39) & PR (40-44) & PR (45-49) & PR(50-54) & PR(55-59) & PR (60-64) & PR (65+) \\
\hline $2002-06$ & 46.0 & 68.1 & 76.0 & 76.8 & 79.7 & 83.3 & 84.9 & 82.2 & 75.1 & 56.3 & 10.9 \\
\hline 2007-12 & 39.9 & 66.3 & 76.4 & 78.4 & 79.7 & 82.4 & 84.0 & 83.6 & 78.9 & 65.6 & 16.4 \\
\hline 2013-14 & 34.5 & 65.8 & 75.5 & 78.0 & 80.8 & 80.7 & 83.7 & 84.0 & 81.3 & 71.5 & 22.3 \\
\hline & Entrants & \multicolumn{2}{|c|}{ Trainees } & \multicolumn{2}{|c|}{ Pre-Peak } & \multicolumn{3}{|c|}{ Peak } & \multicolumn{2}{|c|}{ Post-Peak } & Retirees \\
\hline Variability* & PR (15-19) & PR (20-24) & PR (25-29) & PR (30-34) & PR (35-39) & PR (40-44) & PR (45-49) & PR(50-54) & PR(55-59) & PR (60-64) & PR (65+) \\
\hline $2002-06$ & $4.4 \%$ & $3.2 \%$ & $2.1 \%$ & $2.6 \%$ & $1.0 \%$ & $1.3 \%$ & $1.0 \%$ & $2.0 \%$ & $3.6 \%$ & $5.8 \%$ & $12.1 \%$ \\
\hline $2007-12$ & $14.4 \%$ & $3.5 \%$ & $2.6 \%$ & $1.8 \%$ & $1.1 \%$ & $1.4 \%$ & $0.9 \%$ & $1.0 \%$ & $1.2 \%$ & $3.2 \%$ & $11.9 \%$ \\
\hline \multirow[t]{2}{*}{ 2013-14 } & $0.6 \%$ & $0.3 \%$ & $0.6 \%$ & $0.6 \%$ & $0.6 \%$ & $0.1 \%$ & $0.3 \%$ & $0.6 \%$ & $0.9 \%$ & $3.0 \%$ & $5.7 \%$ \\
\hline & Entrants & \multicolumn{2}{|c|}{ Trainees } & \multicolumn{2}{|c|}{ Pre-Peak } & & Peak & & \multicolumn{2}{|c|}{ Post-Peak } & Retirees \\
\hline
\end{tabular}

B: Participation Rate by age cohorts: Historical (2002-2012 June Qtr) and Forecasts (2013-2014)

\begin{tabular}{|c|c|c|c|c|c|c|c|c|c|c|c|}
\hline Averages & PR (15-19) & PR (20-24) & PR (25-29) & PR (30-34) & PR (35-39) & PR (40-44) & PR (45-49) & PR(50-54) & PR(55-59) & PR (60-64) & PR (65+) \\
\hline $2002-06$ & 53.6 & 73.4 & 79.8 & 79.8 & 82.4 & 85.7 & 86.9 & 84.4 & 77.1 & 58.0 & 11.1 \\
\hline 2007-12 & 50.4 & 73.9 & 81.4 & 82.1 & 82.9 & 85.6 & 87.1 & 86.2 & 81.2 & 67.4 & 16.7 \\
\hline 2013-14 & 45.0 & 75.4 & 81.5 & 82.9 & 84.4 & 84.7 & 87.4 & 87.3 & 84.1 & 74.2 & 21.6 \\
\hline & Entrants & \multicolumn{2}{|c|}{ Trainees } & \multicolumn{2}{|c|}{ Pre-Peak } & \multicolumn{3}{|c|}{ Peak } & \multicolumn{2}{|c|}{ Post-Peak } & Retirees \\
\hline
\end{tabular}

\begin{tabular}{|c|c|c|c|c|c|c|c|c|c|c|c|}
\hline Variability* & PR (15-19) & PR (20-24) & PR (25-29) & PR (30-34) & PR (35-39) & PR (40-44) & PR (45-49) & PR(50-54) & PR(55-59) & PR (60-64) & PR (65+) \\
\hline $2002-06$ & $2.3 \%$ & $2.2 \%$ & $1.4 \%$ & $1.9 \%$ & $0.5 \%$ & $1.0 \%$ & $0.8 \%$ & $1.4 \%$ & $3.1 \%$ & $5.0 \%$ & $12.1 \%$ \\
\hline 2007-12 & $8.4 \%$ & $1.8 \%$ & $1.1 \%$ & $1.2 \%$ & $0.9 \%$ & $0.7 \%$ & $0.7 \%$ & $0.8 \%$ & $1.5 \%$ & $3.8 \%$ & $11.9 \%$ \\
\hline 2013-14 & $0.3 \%$ & $0.2 \%$ & $0.3 \%$ & $0.7 \%$ & $0.3 \%$ & $0.3 \%$ & $0.2 \%$ & $0.4 \%$ & $0.7 \%$ & $2.8 \%$ & $4.2 \%$ \\
\hline & Entrants & \multicolumn{2}{|c|}{ Trainees } & \multicolumn{2}{|c|}{ Pre-Peak } & \multicolumn{3}{|c|}{ Peak } & \multicolumn{2}{|c|}{ Post-Peak } & Retirees \\
\hline
\end{tabular}

* Measured as Co-efficient of Variation 